\title{
Study on spatio-temporal coupling fuzzy control for temperature field in travelling grate
}

\author{
Ou Xie $\mathrm{Xi}^{1,2}$ \\ ${ }^{1}$ School of Mechanical Engineering, Jiangsu University, \\ Zhenjiang, china \\ ${ }^{2}$ School of Mechanical Engineering, Suzhou University of \\ Science and Technology, Suzhou, china \\ hnxieou@126.com
}

\author{
Boquan Li \\ School of Mechanical Engineering, \\ Jiangsu University, \\ Zhenjiang, china \\ ujslibq@163.com
}

\begin{abstract}
In this paper, the grate bed temperature field distribution state was simulated by computational fluid dynamics (CFD) method. Then, a spatio-temporal coupling fuzzy control method for grate bed temperature field control was proposed. Finally, experiments were conducted on a 150 million tons pellet production grate. Experimental results showed that the grate bed temperature fluctuates within $5{ }^{\circ} \mathrm{C}$ 。
\end{abstract}

Keywords-iron ore pellet; grate; CFD; spatio-temporal coupling; fuzzy control

\section{INTRODUCTION}

Travelling grate is one of the key equipment for iron ore pellet production, which is mainly used for pellet drying and preheating. A lot of study results show that unstable grate bed temperature will lead to pellet fracture in drying stage, incomplete oxidation in preheating stage and the service life of grate traveling mechanism decline[1-3].In addition, pellet drying is the main energy consuming part in pellet production, accounting for $1 / 4$ of the total energy consumption[4]. Therefore, reasonable control of the spatial distribution of grate bed temperature field is beneficial to realize energy saving and consumption reduction in pellet production, and improving the yield and quality of the pellet[5]. However, the grate bed temperature field is a complex system coupled heat and mass transfer, and it is impossible to establish an accurate temperature field control model. Furthermore, the grate bed temperature field decreases in the direction of the pellet movement, which demonstrates that the travelling grate is a typical spatio-temporal coupling system. Fuzzy control method does not need the accurate model of the control object, and has strong robustness and fault tolerance, which is widely applied in complex pellet production control[6-8]. However, the traditional fuzzy sets only contain two dimensional information, variable values and fuzzy degree, not taking into account the spatial information. It will cause large governing error for grate bed temperature field control. Li [9] proposed a three domain fuzzy logic controller based on the spatial fuzzy set for the spatially distributed systems, which is feasible for complex grate bed temperature field.

Based on CFD method, the distribution of the great bed temperature field was simulated in this paper, and a spatiotemporal coupling fuzzy controller was designed to realize the

This research is financially supported by Research Innovation Program for College Graduates of Jiangsu Province (Grant no. CXLX12_0623) and National Natural Science Foundation of China (Grant no. 51675245) temperature field control.

\section{WORKING PRINCIPLE OF THE GRATE}

As show in Fig.1, the grate consist of four sections, including blast drying zone, exhaust drying zone, preheat I zone and preheat II zone. The pellet moves slowly on the grate bed and goes through the four sections successively. The hot gas flow past the ore material layer vertically and exchange heat and mass with pellet to complete dehydration, preheating and oxidation.

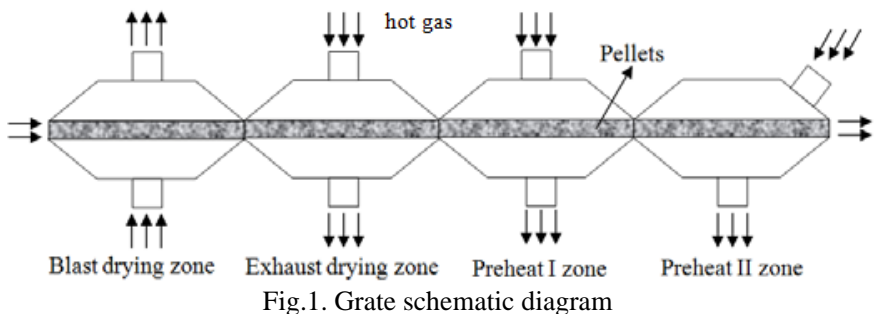

\section{GRATE BED TEMPERATURE FIELD SIMULATION}

A two-dimensional grate bed temperature field simulation model is established base on the grate structure. Fig. 2 shows the partial meshing model of the grate bed temperature field and the simulation parameters are listed in Table I. The $k-\varepsilon$ model in Fluent software is used for model solving.

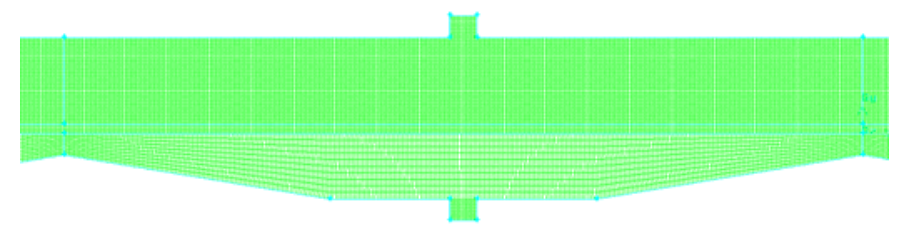

Fig.2. Partial meshing model

TABLEI. SimULATION PARAMETERS

\begin{tabular}{|c|c|c|c|c|}
\hline & $\begin{array}{c}\text { Blast } \\
\text { drying } \\
\text { zone }\end{array}$ & $\begin{array}{c}\text { Exhaust } \\
\text { drying } \\
\text { zone }\end{array}$ & $\begin{array}{c}\text { Preheat } \\
\text { I zone }\end{array}$ & $\begin{array}{c}\text { Preheat } \\
\text { II zone }\end{array}$ \\
\hline Inlet temperature $\left({ }^{\circ} \mathrm{C}\right)$ & 350 & 400 & 800 & 1100 \\
\hline Outlet temperature $\left({ }^{\circ} \mathrm{C}\right)$ & 100 & 200 & 200 & 400 \\
\hline Wind speed(m/s) & 1.5 & 1.5 & 1.5 & 1.5 \\
\hline
\end{tabular}


The distributions of the grate bed temperature field under different times are shown in Fig.3. As can be seen, the temperature distribution is inhomogeneous in space, and the temperature gradually diminishing from the hot gas inlet axis to both sides. In order to avoid excessive temperature rise during pellet drying, the central high temperature area must be monitored.

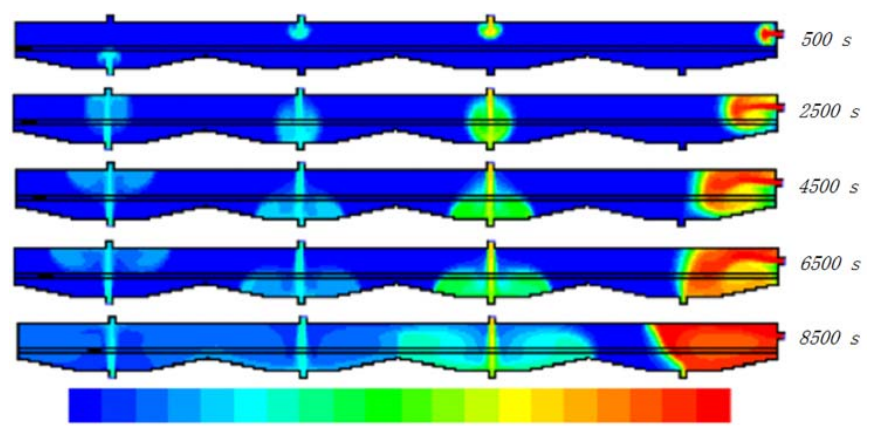

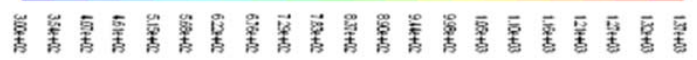

Fig.3. Distribution of temperature field in grate bed

\section{SPATIO-TEMPORAL COUPLING FUZZY CONTROL FOR GRATE BED TEMPERATURE FILED}

According to the simulation results in section III, to avoid the high temperature which leads to the decrease of pellet quality, a series of temperature sensors should be installed from the hot gas inlet axis to both sides in each section. The measured spatial temperature distribution $(\mathrm{i}=1,2, \ldots, \mathrm{p}, \mathrm{p}$ is the number of the temperature sensors) compared with the given temperature to obtain the temperature deviation and temperature deviation variation rate. The whole grate is equipped with four hot gas control system and a spatiotemporal coupling fuzzy controller is employed in each hot gas control system. The structure of the spatio-temporal coupling fuzzy controller is shown in Fig.4.

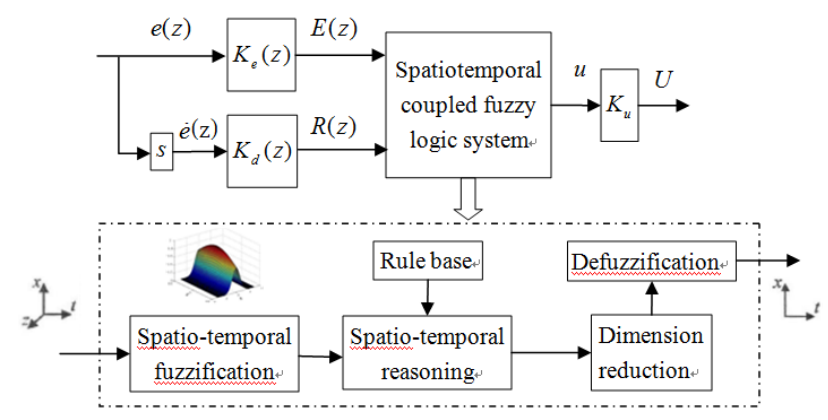

Fig.4. Spatio-temporal coupling fuzzy controller

The spatio-temporal coupling fuzzy controller is designed as follows:

\section{A. Design of membership function of input and output variables}

The input variables of the spatio-temporal coupling fuzzy controller are temperature deviation $E(z)=K_{e} e(z)$ and temperature deviation variation rate $R(z)=K_{d} \dot{e}(z)$.The spatiotemporal fuzzy sets of the input variables $E(z)$ are given by

$$
\left\{\bar{A}_{-N}, \ldots, \bar{A}_{-1}, \bar{A}_{0}, \bar{A}_{1}, \ldots \bar{A}_{N}\right\}
$$

The spatio-temporal fuzzy sets of the input variables $R(z)$ are given by

$$
\left\{\bar{B}_{-N}, \ldots, \bar{B}_{-1}, \bar{B}_{0}, \bar{B}_{1}, \ldots \bar{B}_{N}\right\}
$$

The membership of input fuzzy sets are given by

$$
\left\{\mu_{-N}(x, z), \ldots, \mu_{-1}(x, z), \mu_{0}(x), \mu_{1}(x), \ldots \mu_{N}(x)\right\}
$$

Where, $\quad x \quad$ indicates $E(z)$ or $R(z)$, $\mu_{i}(x, z)=\left(\mu_{i}\left(x(z), \mu_{i}(z)\right)\right), \mu_{i}(x(z))$ is the time membership function, $\mu_{i}(z)$ is the spatial membership function.

The spatio-temporal fuzzy sets of input variables are interval fuzzy sets. The spatio-temporal membership function as shown in Fig.5.

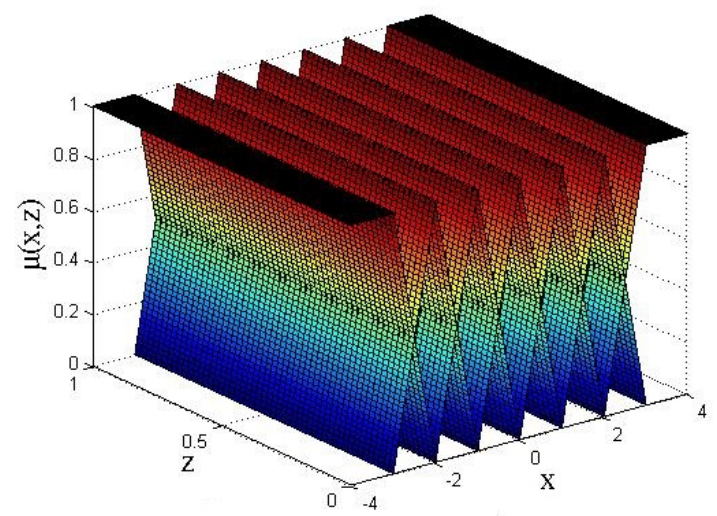

Fig.5. Spatio-temporal membership function

The output variables of the spatio-temporal coupling fuzzy controller are hot gas control variable $U=K_{u} u(x)$.The spatiotemporal fuzzy sets of the output variables $U$ are given by

$$
\left\{\bar{G}_{-2 N}, \ldots, \bar{G}_{-1}, \bar{G}_{0}, \bar{G}_{1}, \ldots \bar{G}_{2 N}\right\}
$$

\section{B. Spatio-temporal fuzzification}

The input variables of the spatio-temporal coupling fuzzy controller are temperature deviation and temperature deviation variation rate and the output of the spatio-temporal coupling fuzzy controller is the hot gas control variable. The input spatio-temporal fuzzy sets of grate bed temperature deviation and temperature deviation variation rate can be show as 


$$
\left\{\begin{array}{l}
\bar{A}_{i}=\sum_{z \in R^{n}} \sum_{e(t) \in E}\left(f_{z}(e(t)), f_{e(t)}(z)\right) /(e(t), z) \\
\bar{B}_{j}=\sum_{z \in R^{n}} \sum_{\dot{e}(t) \in R}\left(f_{z}(\dot{e}(t)), f_{\dot{e}(t)}(z)\right) /(\dot{e}(t), z)
\end{array}\right.
$$

\section{Rule base}

The general linear rule of the two input spatio-temporal fuzzy logic control system can be written as follows:

$$
R^{l} \text { :if } E(z) \text { is } \bar{A}_{i} \text { and } R(z) \text { is } \bar{B}_{j} \text { then } u \text { is } \bar{G}_{k}
$$

Where, $E(z)=K_{e} e(z)$ and $R(z)=K_{d} \dot{e}(z)$ are input variables, $\bar{A}_{i}$ and $\bar{B}_{j}(i, j=-N, \ldots,-1,0,1, \ldots, N)$ are input spatio-temporal fuzzy sets, $u$ is output control variable, $\bar{G}_{k}(k=-2 N, \ldots,-$ $1,0,1, \ldots, 2 N)$ is output spatio-temporal fuzzy sets.

For an arbitrary space position $z$, a spatio-temporal linear rule library can be established as shown in Table II, in which the domain of input spatio-temporal fuzzy sets is [-3 3] and the domain of output spatio-temporal fuzzy sets is [-6 6].

TABLE II. FUZZY RULE TABLE

\begin{tabular}{|c|c|c|c|c|c|c|c|}
\hline $\begin{array}{c}\boldsymbol{R}(\mathbf{z}) / \\
\boldsymbol{E}(\mathbf{z})\end{array}$ & $\bar{A}_{-3}$ & $\bar{A}_{-2}$ & $\bar{A}_{-1}$ & $\bar{A}_{0}$ & $\bar{A}_{1}$ & $\bar{A}_{2}$ & $\bar{A}_{3}$ \\
\hline $\bar{B}_{3}$ & $\bar{G}_{0}$ & $\bar{G}_{1}$ & $\bar{G}_{2}$ & $\bar{G}_{3}$ & $\bar{G}_{4}$ & $\bar{G}_{5}$ & $\bar{G}_{6}$ \\
\hline $\bar{B}_{2}$ & $\bar{G}_{-1}$ & $\bar{G}_{0}$ & $\bar{G}_{1}$ & $\bar{G}_{2}$ & $\bar{G}_{3}$ & $\bar{G}_{4}$ & $\bar{G}_{5}$ \\
\hline $\bar{B}_{1}$ & $\bar{G}_{-2}$ & $\bar{G}_{-1}$ & $\bar{G}_{0}$ & $\bar{G}_{1}$ & $\bar{G}_{2}$ & $\bar{G}_{3}$ & $\bar{G}_{4}$ \\
\hline $\bar{B}_{0}$ & $\bar{G}_{-3}$ & $\bar{G}_{-2}$ & $\bar{G}_{-1}$ & $\bar{G}_{0}$ & $\bar{G}_{1}$ & $\bar{G}_{2}$ & $\bar{G}_{3}$ \\
\hline $\bar{B}_{-1}$ & $\bar{G}_{-4}$ & $\bar{G}_{-3}$ & $\bar{G}_{-2}$ & $\bar{G}_{-1}$ & $\bar{G}_{0}$ & $\bar{G}_{1}$ & $\bar{G}_{2}$ \\
\hline $\bar{B}_{-2}$ & $\bar{G}_{-5}$ & $\bar{G}_{-4}$ & $\bar{G}_{-3}$ & $\bar{G}_{-2}$ & $\bar{G}_{-1}$ & $\bar{G}_{0}$ & $\bar{G}_{1}$ \\
\hline $\bar{B}_{-3}$ & $\bar{G}_{-6}$ & $\bar{G}_{-5}$ & $\bar{G}_{-4}$ & $\bar{G}_{-3}$ & $\bar{G}_{-2}$ & $\bar{G}_{-1}$ & $\bar{G}_{0}$ \\
\hline
\end{tabular}

D. Spatio-temporal reasoning

The reasoning machine maps the spatio-temporal fuzzy input $\bar{A}_{X}$ into a spatio-temporal fuzzy set $\bar{W}^{l}$.

$$
\bar{W}_{\bar{A}_{X} \circ \bar{R}^{l}}^{l}=\bar{A}_{X} \circ\left(\bar{A}^{l} \otimes \bar{B}^{l} \rightarrow \bar{G}^{l}\right)
$$

Where, “ $\circ$ ” indicates the synthetic operation with the MaxMin method. follows:

The spatio-temporal membership function is expressed as

$$
\begin{aligned}
& \mu_{\bar{W}^{l}}(u, z)=\sup _{x(z) \in X}\left\lfloor\mu_{\bar{A}_{X}} * \mu_{\bar{A}^{l} \otimes \bar{B}^{l} \rightarrow \bar{G}^{l}}(x(z), u, z)\right\rfloor \\
& =\sup _{x(z) \in X}\left\{\begin{array}{l}
\mu_{\bar{A}_{X}} * \mu_{\bar{A}^{\prime}}(x(z), u, z)^{*} \mu_{\bar{B}^{l}}(x(z), u, z) \\
* \mu_{\bar{G}^{l}}(x(z), u, z)
\end{array}\right\} \\
& =\left(\mathrm{F}_{x}(u), 1\right)
\end{aligned}
$$

Where $x(z)=[E(z), R(z)]$.

\section{E. Output processing}

The output processing consists of two operations: dimension reduction and conventional defuzzification. The purpose of dimension reduction is to compress spatial information. The spatio-temporal membership function $\mu_{\bar{W}^{l}}(u, z)$ can be converting to traditional membership function $\mu_{t}^{l}(u)$ by using the "center-of-sets" calculation methods and the weighting factors $\omega\left(z_{p}\right)>0(p=1, \ldots, n)$ are employed. For each triggering rule, the spatial weighted and dimensionality reduction information is output as follows:

$$
\mu_{t}^{l}(u)=\frac{\sum_{p=1}^{n} F_{x_{p}}^{l}(u) \omega\left(z_{p}\right)}{\sum_{p=1}^{n} \omega\left(z_{p}\right)}
$$

According to the pellet drying and preheating process, the temperature sensor $i$ mounted on the hot gas inlet axis should be assigned with large weighting factor. The weighting factors of the other monitoring points should be smaller than that of the temperature sensor $i$, furthermore, the farther away from the sensor $i$, the smaller the weighting factor. The weighting factors should meet the formula $\sum_{p=1}^{n} \omega\left(z_{p}\right)=1$. From the above analysis, the space weighting factors can be designed as follows

$$
\left\{\begin{array}{c}
\omega^{l}\left(z_{p}\right)=\frac{1}{|i-p| * n}(p=1,2, \ldots, n ; p \neq i) \\
\omega^{l}\left(z_{p}\right)=1-\sum_{p=1}^{i-1} \omega^{l}\left(z_{p}\right)-\sum_{p=i+1}^{n} \omega^{l}\left(z_{p}\right)(p=i)
\end{array}\right.
$$

After the dimension reduction, the traditional fuzzy set output is obtained. The "center-of-set" defuzzification method is employed to calculate the control output as follows:

$$
u=\frac{\sum_{l=1}^{L} c^{l} \mu_{t}^{l}(u)}{\sum_{l=1}^{L} \mu_{t}^{l}(u)}
$$

Where, $c^{l} \in U$ indicates the central value of the conclusion set $G^{l}$ of the triggering rules $R^{l}(l=1,2, \ldots, L)$. $L$ indicates the total number of triggered rules.

\section{EXPERIMENT}

In this paper, experiments were conducted on a 150 million tons pellet production grate. The spatio-temporal coupling fuzzy controller was employed for hot gas control in each section. The temperature sensor is installed as shown in Fig.6. As shown in Table III, the measured average temperature in grate bed can be stabilized at a given value. 


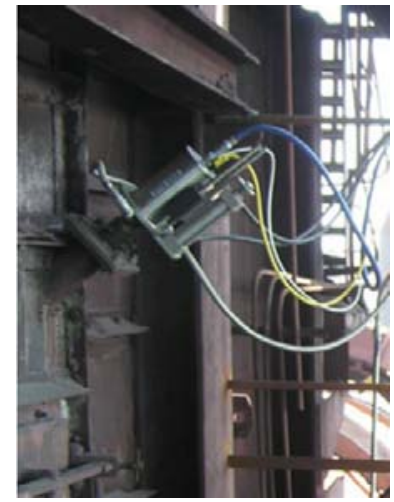

Fig. 6. Installation schematic of temperature sensor

TABle III. Temperature test VALUe

\begin{tabular}{|c|c|c|c|c|}
\hline $\begin{array}{c}\text { Process } \\
\text { zone }\end{array}$ & $\begin{array}{c}\text { Blast } \\
\text { drying zone }\end{array}$ & $\begin{array}{c}\text { Exhaust } \\
\text { drying zone }\end{array}$ & $\begin{array}{c}\text { Preheat } \\
\text { I zone }\end{array}$ & $\begin{array}{c}\text { Preheat } \\
\text { II zone }\end{array}$ \\
\hline $\begin{array}{c}\text { ideal } \\
\text { value }\end{array}$ & 200 & 400 & 650 & 1050 \\
\hline $\begin{array}{c}\text { measured } \\
\text { value }\end{array}$ & 205 & 397 & 652 & 1055 \\
\hline
\end{tabular}

\section{CONCLUSIONS}

In this paper, the spatio-temporal distribution characteristics of the grate bed temperature field were analyzed by CFD simulation. A spatio-temporal coupling fuzzy controller was designed for grate bed temperature field control. The experiments results shown that the designed controller can realize the precise control of grate bed temperature field.

\section{ACKNOWLEDGMENT}

This research is financially supported by Research Innovation Program for College Graduates of Jiangsu Province (Grant no. CXLX12_0623) and National Natural Science Foundation of China (Grant no. 51675245)

\section{REFERENCES}

[1] S.J.Pan, Y. P.Song, X.Q.Peng, "Numerical simulation for coupled multifield transfer on pellet drying process in travelling grate". Research on Iron \& Steel, vol. 40, pp. 11-15, June 2010

[2] M. Barati, "Dynamic simulation of pellet induration process in straight system”. Int.J.Miner.Process, vol.89,pp. 30-39, 2008

[3] A.L.Ljung, T. S.Lundstrom, B. D.Marjavaara. "Convective drying of an individual iron ore pellet-Analysis with CFD”. International Journal of Heat and Mass Tranfer,vol.54, pp.3882-3890, 2011.

[4] A.L.Ljung, T. S.Lundstrom, K.Tano. "Simulation of heat transfer and fluid flow in a porous bed of iron ore pellets during up-draught drying". Fifth international conference on CFD in the process industries, CSIRO, Melbourne, Australia.

[5] F.Patisson, J.P.Bellot, Ablitzer. "Study of moisture transfer during the strand sintering process. Metall”. Trans., B, Process Metall, vol. 21B, pp.37-47, 1990.

[6] F.X.Gao, B.Q.Li, L.J.Ding, J.J.Huang. "Research and simulation of Fuzzy-PID control for chain-grate bed temperature field". Microcomputer Information, vol.25, pp.42-43, June, 2009.

[7] S.C. Xu, B. Wang, Y.W.Jing“Design of fuzzy decoupling control of temperature field in grate-rotary kiln”. Sintering and Pelletizing, vol.35, pp.25-29, April, 2010.
[8] B.Q.Li, F.X.Gao, L.J.Ding. "Design of chain-grate bed temperature intelligent controller based on S7-300". Sintering and Pelletizing, vol.33, pp.11-33, June, 2008.

[9] H.X.Li, X.G.Duan, Z.Liu, "Three-dimensional fuzzy logic system for process modeling and control”,Journal of Control Theory and Application, vol.3, pp.280-285, August, 2010. 